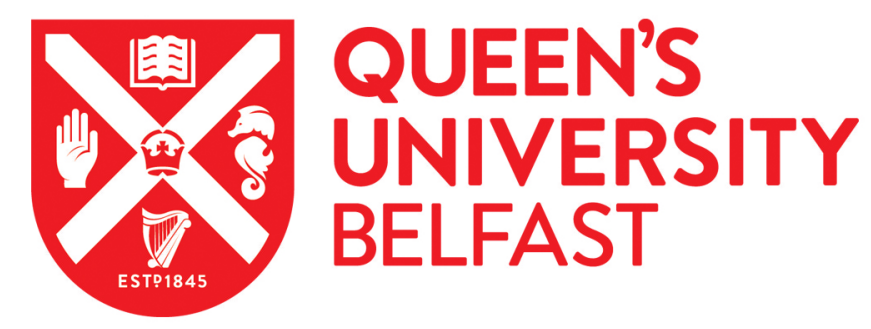

\title{
From injustice to action: the role of empathy and perceived fairness to address inequality via victim compensation
}

Urbanska, K., McKeown, S., \& Taylor, L. K. (2019). From injustice to action: the role of empathy and perceived
fairness to address inequality via victim compensation. Journal of Experimental Social Psychology, 82, 129-140.
https://doi.org/10.1016/j.jesp.2019.01.010

Published in:

Journal of Experimental Social Psychology

Document Version:

Peer reviewed version

Queen's University Belfast - Research Portal:

Link to publication record in Queen's University Belfast Research Portal

Publisher rights

Copyright 2019 Elsevier.

This manuscript is distributed under a Creative Commons Attribution-NonCommercial-NoDerivs License

(https://creativecommons.org/licenses/by-nc-nd/4.0/), which permits distribution and reproduction for non-commercial purposes, provided the author and source are cited.

\section{General rights}

Copyright for the publications made accessible via the Queen's University Belfast Research Portal is retained by the author(s) and / or other copyright owners and it is a condition of accessing these publications that users recognise and abide by the legal requirements associated with these rights.

Take down policy

The Research Portal is Queen's institutional repository that provides access to Queen's research output. Every effort has been made to ensure that content in the Research Portal does not infringe any person's rights, or applicable UK laws. If you discover content in the Research Portal that you believe breaches copyright or violates any law, please contact openaccess@qub.ac.uk. 


\title{
FROM INJUSTICE TO ACTION: THE ROLE OF EMPATHY AND PERCEIVED FAIRNESS TO ADDRESS INEQUALITY VIA VICTIM COMPENSATION
}

\begin{abstract}
Acting prosocially towards others may sometimes involve tangible costs to self, which can be associated with lower motivation to help those who have been the victims of injustice. In contrast to previous work which suggests that empathy does not shape the perceptions of injustice, the present research proposes that while perceptions of fairness in the context of injustice are dynamic, they may well be shaped by empathy. Using a dictator-style paradigm, the present research explored the extent to which empathy is related to perceptions of injustice and in turn, compensating forms of inequality. A non-registered Study $1(\mathrm{~N}=466)$ found that higher empathy predisposition is related to perceiving more injustice in contexts of inequality. Preregistered Study $2(\mathrm{~N}=406)$ extended this finding by experimentally manipulating empathy, showing that emphasising with the victim of inequality is indirectly related to perceiving injustice. The hypothesised mechanism, empathy allowing identification and experiencing the feelings of anger associated with the injustice, is supported in Study 2. As such, perceptions of fairness are not static; empathy is argued to be an important mechanism in forming justice perceptions. Data and supplementary materials: [DOI: https://doi.org/10.17605/OSF.IO/83V4U].
\end{abstract}

\section{Highlights}

- Fairness is not about commonly agreed rules but about dynamic judgements

- Empathy enables individuals to feel what it is like being a victim of inequality

- Empathy lets individuals to infer anger from the victim and feel anger themselves

- Increased anger explains why empathy leads to perceiving inequality as more unfair

Keywords: injustice, fairness, compensation, empathy, dictator games, registered report 
From injustice to action: The role of empathy and perceived fairness to address inequality via victim compensation

For decades, researchers have been concerned with understanding the conditions under which individuals who observe injustice are motivated to engage in prosocial actions to help the victim (Eagly \& Crowley, 1986; Hoffman, 2008; Small \& Simonsohn, 2008). Whilst a number of factors have emerged (for a comprehensive review, see Penner, Dovidio, Piliavin, \& Schroeder, 2005), empathy appears to be one of the most important predictors of compensatory behaviours (Eisenberg \& Mussen, 1989), such that individuals who are more empathetic are more likely to help. In other words, being able to vicariously experience another person's emotional state motivates helping behaviours. However, when resources are scarce, individuals are more likely to engage in behaviours which benefit themselves, rather than help others, and may even blame the victim for their misfortune (Lerner, 1980). Therefore, the mechanisms under which individuals act prosocially, to reduce inequality at their own expense, are still relatively unknown.

There is a wide scientific consensus that empathy, described as a disposition to feel a concern for victims, increases the likelihood of compensation behaviour in the context of injustice (Leliveld, Van Dijk, \& Van Beest, 2012). We extend this research by questioning whether empathy directly influences prosocial behaviour by proposing that empathy may shape what is perceived to be fair in the first place. This perceived fairness, in turn, influences the likelihood that people are willing to reduce resource inequality at the expense of self-interest. Therefore, the present research tests the assertion that perceived fairness in such situations is not static or widely agreed but rather, it is influenced by the empathetic processing of injustice.

\section{The Altruism-Empathy Hypothesis}

Children as young as 18 months exhibit predispositions for prosocial behaviours by sharing or helping others (Dunfield, Kuhlmeier, O'Connell, \& Kelley, 2011). These acts tend to increase in complexity and frequency with age (Dunn \& Munn, 1986), but what they have in common is that their primary aim is to benefit others (Eisenberg \& Fabes, 1998). Researchers argue that in some cases, 
truly selfless acts of kindness are motivated uniquely by the wellbeing of the affected individual (Batson, 1991, 1998). This is often referred to as altruism, a form of prosocial behaviour that is not driven by self-interest. Empathy has been identified as fundamental to such behaviours (Eisenberg \& Mussen, 1989); it requires awareness of others' states, thoughts, and feelings. Toward this end, feelings of empathy are essential for helping those in need (Coke, Batson, \& McDavis, 1978).

There are competing accounts on the underlying motivations that link empathy and prosocial behaviours. On the one hand, some argue that prosocial behaviours are rarely truly altruistic. For example, Cialdini and colleagues propose that empathic concern stems from blurring the boundaries between the self with the other, such that prosocial behaviours become acts towards oneself (Cialdini, Brown, Lewis, Luce, \& Neuberg, 1997). In a series of studies, they demonstrated that feelings of sadness, and not empathy itself, motivated prosocial behaviours. Based on these findings, they concluded that people have egoistic desires to relieve themselves of the negative emotions (Cialdini et al., 1987). On the other hand, there is an argument against these types of egoistic explanations, claiming there is weak evidence that prosocial actions are aimed at reducing one's own unpleasant emotions (Batson, 1991).

Regardless of the motivations underlying prosocial acts, the impact of carrying out such behaviours is arguably positive. Studies demonstrate that the induction of empathy may increase helping behaviour in a variety of contexts, even towards stigmatised groups such as drug addicts (Batson, Chang, Orr, \& Rowland, 2002). These experimental studies typically measure prosocial behaviours by asking participants to state the extent to which they would help or allocate resources to a victim of injustice. There are often discrepancies, however, between intended and actual helping behaviours (Vezzali et al., 2015). When asked about intended behaviours, there is often no obvious cost to the participant which would prevent them from helping; if anything, helping or other forms of compensation may be socially desirable which may decrease confidence in external validity of such measures. Dictator-style games, however, developed ways to measure actual prosocial behaviour. They typically involve observing a player distribute resources to another passive recipient (see McAuliffe, Blake, Steinbeis, \& Warneken, 2017 for other types of economic games) and thus, they 
have a potential to measure the real response to an experience of injustice committed against a victim within an experimental paradigm.

Compensating or helping the victim, of course, is not the only way to respond to inequalities. Some people may instead choose to punish the perpetrator (Fehr \& Gächter, 2002; Gromet \& Darley, 2009). The preference for punishment over compensation appears to be stronger in criminal cases, the reverse is only observed when the victim is psychologically closer to the person making those decisions (van Prooijen, 2010). This finding is supported by laboratory-based evidence, which shows that empathy drives both compensation and punishment behaviours but in different ways (Leliveld et al., 2012). Namely, highly empathetic individuals address inequality by focusing on the victim and compensating them, while low empathetic individuals address inequality by focusing on the perpetrator and punishing them. Our primary interest in this research lies in the empathy-driven reduction of inequality, so we focus on compensation behaviours only.

Whilst there is a considerable amount of research that has examined the relationship between empathy and prosocial behaviour either via compensation or punishment (Leliveld et al., 2012; Weng, Fox, Hessenthaler, Stodola, \& Davidson, 2015; Will, Crone, Bos, \& Güroğlu, 2013), to the best of our knowledge, researchers have rarely considered whether and how empathy may affect perceived fairness of unequal distributions. We aim to address this omission and argue that perceived fairness, as opposed to the objective distribution of resources, is central to understanding how empathy affects prosocial behaviours.

\section{Empathy and Perceived Fairness in Resource Distribution}

Perceived fairness is related to the equal or unequal distribution of resources (for a review, see Starmans, Sheskin, Bloom, Christakis, \& Brown, 2017) and is central in enabling compensatory actions in economic games (Schroeder, Steel, Woodell, \& Bembenek, 2003) as well as in applied settings such as collective action (van Zomeren, Spears, Fischer, \& Leach, 2004). That is, a level of unfairness needs to be acknowledged in order to motivate individuals to act prosocially. At the same time, fairness perceptions are influenced by who the actor is; one's own behaviour is typically judged 
as more fair compared to the behaviour of others (Messick, Bloom, Boldizar, \& Samuelson, 1985). As such, standards of fairness are not always applied impartially. Evidence for this assertion comes from Lupfer, Weeks, Doan, and Houston (2000), who found that different rules were used to evaluate unequal distributions given to the self, compared to a third party. More specifically, the authors concluded that when a third party receives unequal outcomes, people are more likely to use distributive justice rules to evaluate the situation (e.g., was the outcome even?), but when the individuals themselves are the recipients of the same unequal outcome, they are more likely to utilise procedural justice rules (e.g., how was the decision about the outcome made?). Thus, by emphasising different fairness rules for the self versus the other, participants may arrive at a divergent understanding of what is fair in response to the same unequal outcome.

Furthermore, in intergroup contexts, groups judge rules that favour their own group as more fair than rules that favour the outgroup (Platow, Hunter, Branscombe, \& Grace, 2014) and judge harsh behaviour towards an outgroup as more fair than if it happened to the ingroup (Radburn, Stott, Bradford, \& Robinson, 2016). Therefore, the relationship between unequal distributions and its perceived fairness is not linear or static; people can accept unequal distributions, as long as they are justifiable, but are most adverse to unfair distributions (Starmans et al., 2017). Yet, it is perceptions of unfairness that are more vulnerable to subjectivity than perceptions of inequality. This calls for an understanding of what factors, other than group membership, may influence perceived fairness. Given the links between empathy and prosocial behaviour, and between perceived fairness and prosocial behaviour, we argue that empathy may shape perceptions of fairness.

When deciding how fair a situation is, empathetic concern may influence how a victim's emotions are taken into account. For example, individuals lower in empathy may be more likely to detach themselves from the victim and judge fairness from the perspective of an unaffected third-party observer (Cialdini et al., 1997). At the same time, those higher in empathy may be more responsive to how the victim is feeling, and in turn, and motivated to act based on their perceptions of victim's emotions. Understanding how people arrive at judgements of fairness, therefore, may not be as simple as assuming that these judgements are based on a normative understanding of what fairness is or is 
not. We argue that empathy may be a useful lens to understand how perceived fairness is formed and how it, in turn, influences compensation behaviours. If individuals who feel greater concern for a victim of inequality also perceive a distribution as less fair, compared to those who do not feel concern for the victim, this challenges the notion that people widely share an understanding of fairness (Messick, 1995). In other words, empathy may be related to what is considered fair, even if the distributions are clearly equal or unequal.

Despite these potential links, the hypothesis that empathy may influence how people perceive fairness in contexts of inequality has not been thoroughly investigated. Research carried out by Leliveld et al. (2012, Study 1) found that those higher in empathy were more likely to compensate the victim of inequality than those lower in empathy; when there was no inequality, empathy levels did not affect the compensation behaviour. The authors argued that this finding links to previous research which demonstrates that equity may be associated with a shared norm of fairness, arguing against the idea that empathy may influence how people perceive fairness in contexts of inequality. We argue, however, that empathy may inform perceived fairness which, in turn, will influence compensatory behaviour, even when this means forgoing self-interest. Following Cialdini et al. (1997)'s reasoning, the present research argues that by empathising with the victim, the line between the self and the other becomes blurred. Given that previous research demonstrates that what is considered fair is rarely impartial (Lupfer et al., 2000; Messick et al., 1985; Platow et al., 2014; Radburn et al., 2016), we argue that perceptions of fairness can be further shaped by empathy for victims of inequality. Empathy, as the ability to accurately read others' emotional states, allows individuals to be responsive to injustices directed at another person and to perceive unfairness on their behalf. In other words, unfairness may be claimed more readily amongst empathetic individuals in contexts of inequality. Conversely, lack of empathy for the victim may prompt emotionally-detached perceptions of fairness. In that case, what is considered fair or unfair would be decided with a lesser consideration on how the victim of the injustice may feel.

\section{Present Research}


Our research aims to examine the roles that both empathy and perceived fairness play in understanding prosocial behaviours. We test two competing hypotheses regarding the moderating role of empathy (Figure 1). First, we consider the model put forward by Leliveld et al. (2012) in which empathy moderates the relationship between dictator offer and compensation. Second, we propose a moderated mediation model whereby empathy moderates the relationship between dictator offer and perceived fairness. To this end, the paper consists of a non-registered study (Study 1) which provides an initial test for the primary hypothesis that empathy is related to perceived fairness depending on whether the dictator offer is more or less equal. The paper also includes a pre-registered study (Study 2) that manipulates empathy experimentally and assesses the role of emotions underlying empathydriven perceived fairness. Given concerns surrounding the external validity of measuring self-reported prosocial behaviours, we employ a dictator-style game to investigate the mechanisms underlying thirdparties addressing inequalities.

(a)

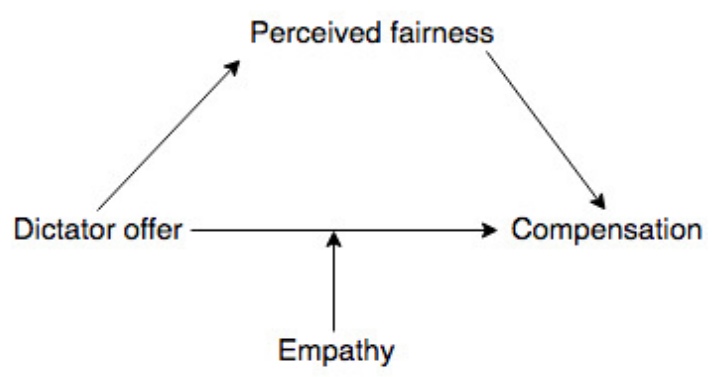

(b)

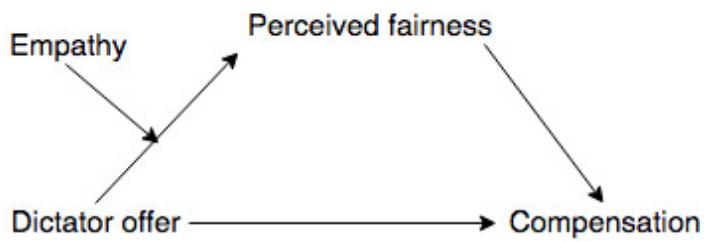

Figure 1. Comparison of the two models tested in Study 1. (a) Model proposed by Leliveld et al.

(2012) whereby empathy moderates the relationship between dictator offer and compensation; (b) The primary hypothesis: a moderated mediation model whereby empathy moderates the relationship between dictator offer and perceived fairness.

We build our experimental paradigm on previous research carried out by Leliveld et al. (2012; Study 1; see also Fehr \& Fischbacher, 2004 for a similar paradigm). In this study, participants (Player 
$\mathrm{C}$, the observer) were invited to the laboratory to play a game with two other players (Player A, the dictator, and Player B, the victim) who were allegedly in another room. Participants were told that Player A's (the dictator's) task was to share one hundred of their coins in 10-coin increments with Player B (the victim) in the first round. Participants were informed about the size of the dictator's offer and, in the subsequent round, could choose to share up to a total of fifty of their own coins with the victim. Participants subsequently rated the fairness of each dictator offer. This procedure was repeated in an increasing fashion until participants saw all dictator offers from 0 and 50 coins.

We extend Leliveld et al.’s (2012) research in multiple ways. First, we make a theoretical contribution by examining the hypothesis that empathy shapes perceived fairness. We conceptualise fairness as a dynamic concept, influenced by individuals' experiences and emotional capacity. As such, empathising with a victim of injustice can lead to perceiving (in)justice through their eyes, a mechanism which underpins compensation behaviour. Second, we offer an additional test of our primary hypothesis via a pre-registered study (Study 2), which further examines emotions which, in the context of inequality, may explain why high empathisers perceive more unfairness than low empathisers. While Study 1 of Leliveld et al. (2012) used a within-group design to manipulate dictator offer, this could have resulted in anchoring of the subsequent responses in relation to the previous response; thus, we follow the improved, between-group design in their Study 2.

\section{Study 1: Non-registered study}

The purpose of Study 1 was to provide initial evidence for the hypothesis that empathy is crucial in perceptions of injustice, which in turn, may be associated with higher likelihood to help the victim of injustice. The data comes from a larger, longitudinal project on positive youth development.

\section{Method}

\section{Participants}


Adolescents from Northern Ireland aged 14-15 ( $\mathrm{N}=466,50 \%$ male, 50\% female) participated in the study between February and March $2016^{1}$. The research team visited eight secondary schools where the students participated in the study in groups of around 30, during one of their classes. All data was self-report and collected online via Qualtrics. There were no exclusions as there was no missing data. Students who completed two waves of the study were compensated with a $£ 10$ Amazon voucher and each of the eight schools received a $£ 100$ Amazon voucher.

\section{Procedure and Materials}

Details of all measures as well as the list of variables included as a part of this research are available via Open Science Framework: https://osf.io/83v4u/.

Empathy. First, participants' empathy and perspective taking was measured using items from Davis' (1980) scale which originally included empathy, perspective taking, and personal distress subscales. In the present research, only the former two subscales were used. While these subscales consisted of 14 items, only items appropriate for adolescents were selected. Participants responded to nine items on a seven-point scale $(1=$ strongly disagree; 7 = strongly agree $)$. Both subscales had initially poor internal reliability (perspective-taking $\alpha=.54$, empathy $\alpha=.53$ ) which prompted the decision to explore the structure of all of the items via factor analysis as a first step in the analytic procedure. This resulted in a single measure of empathy comprising five items $(\alpha=.67$; see Table 1$)$.

Dictator Game. The structure of the keep-compensate game largely followed that of Leliveld et al. (2012; Study 1). In the online game, participants were told they would observe two pupils from other schools in Northern Ireland, Player A (who was the dictator) and Player B (who was the victim), playing a game. Participants were told they could keep the money they had at the end of the game, but they all were compensated equally in the study. Player A was a recipient of one hundred 10-pence

\footnotetext{
${ }^{1}$ The sample size was determined based on the main independent variable in the study design, i.e., whether the school was predominantly Protestant or Catholic as well as whether it was located close to an interface area (where Protestant and Catholic areas meet) or not.
} 
coins (i.e., a total of $£ 10$, the amount the participants were to be compensated in the longitudinal study) and was asked to divide these between themselves and Player B. At this stage, participants were assigned to one out of six conditions whereby Player A gave varying amounts of coins to Player B, ranging from 0 to 50 coins in 10-pence coin increments (i.e., up to £5) creating six conditions (coded 0 $=0$ coins to $5=50$ coins); higher scores reflected higher (i.e., more equal) dictator offers. In the subsequent round of the game, participants were invited to join the game as Player C. They were given fifty 10-pence coins and informed they could either keep all the coins to themselves or give any amount in 10-coin increments to Player B. This variable was called compensation, with a higher score indicating higher compensation level $(0=$ no compensation/ 0 coins; $5=$ full compensation/50 coins $)$.

\section{Table 1}

Factor loadings for empathy and perspective-taking items.

Factor

**I sometimes find it difficult to see things from the 'other person's' point of view (R)

*When I see someone being taken advantage of, I feel kind of protecting towards them

**I sometimes try to understand my friends better by imagining how things look from their perspective

*Other people's misfortunes do not usually disturb me a great deal (R)

**If I'm sure I'm right about something, I don't waste much time listening to other people's arguments $(\mathrm{R})$

*When I see someone being treated unfairly, I sometimes don't feel very much pity for them

*I am often quite affected by things that I see happen

**I believe that there are two sides to every question and try to look at them both

**When I'm upset at someone, I usually try to "put myself in their shoes" for a while

Note. ${ }^{*}=$ empathy items, ${ }^{* *}=$ perspective-taking items; $(\mathrm{R})=$ reverse-coded. Factor loadings below .40 are supressed. Bold items retained as final empathy scale 
Perceived Fairness. Finally, following the same order as Leliveld et al., participants were reminded of the distribution of coins from Player A (the dictator) to Player B (the victim) and were asked to indicate the extent to which they felt that this distribution was fair via three items as following: "How fair do you think Player A was in the allocation of the coins to Player B?" $(1=$ very unfair, 7 = very fair), "How just do you think Player A was in the allocation of the coins to Player B?" $(1=$ very unjust, $7=$ very just $)$ and "How appropriate was the offer?" $(1=$ very inappropriate, $7=$ very appropriate). Three items were aggregated; a higher score indicated higher perceived fairness ( $\alpha=$ $.84)$.

In summary, the present study differed from Leliveld et al. (2012, Study 1) in two ways. First, our study was carried out online in schools rather than in the laboratory. However, evidence suggests that economic games data collected using crowdsourcing sites is largely similar to that obtained in the laboratory, even with low stakes (Amir, Rand, \& Gal, 2012). Second, we did not employ the multiplier function, whereby the compensation (and, punishment alike) was tripled, as we wanted the compensation to be linked to the $£ 10$ participants knew they would be receiving following completion of the study. Moreover, we were working with adolescents with a range of academic abilities and who had limited time to complete a longer questionnaire. We therefore, wanted to decrease the cognitive load in making decisions in the context of this game.

\section{Results}

Given that females tend to be more prosocial than males (Eisenberg, Miller, Shell, McNalley, \& Shea, 1991), the gender of the participants was controlled for across the primary analyses. Firstorder correlations are presented in Table 2 while the mean and standard deviations of perceived fairness and compensation in response to the six dictator offer conditions are presented in Table 3 . We tested two mediated moderation models to investigate whether (a) empathy moderates the relationship between the dictator offer and perceived fairness or (b) empathy moderates the relationship between the dictator offer and compensation behaviour, respectively (see Figure 1). 
Empathy as a Moderator of Dictator Offer-Compensation link. First, a moderated mediation analysis was carried out to test the model supported by Leliveld et al. (2012; see Figure 1a) while controlling for the effects of gender. The model was tested using PROCESS Model 5 (Hayes, 2012 ) with 10,000 bootstrapped samples. Gender as a covariate was not a significant predictor of perceived fairness, $b=-.03$, se $=.12, p=.818$, but it predicted compensation behaviour with females compensating the victims more than males, $b=.37$, se $=.12, p=.002,95 \% \mathrm{CI}[.14, .61]$. A higher dictator offer (more equal, $1 \mathrm{SD}$ above the mean) was associated with higher perceived fairness, $b=$ .46 , se $=.03, p<.001,95 \% \mathrm{CI}[.39, .52]$ and higher perceived fairness, in turn, was related to lower compensation behaviour, $b=-.14$, se $=.05, p=.004,95 \%$ CI $[-.23,-.05]$. The direct path between dictator offer and compensation behaviour was non-significant, $b=-.28$, se $=1.76, p=.874$. Higher empathy further predicted higher compensation behaviour, $b=.31$, se $=.12, p=.008,95 \% \mathrm{CI}[.08$, .53 , but the interaction between dictator offer and empathy was non-significant, $b=-.02$, se $=.04, p$ $=.502$. In other words, self-reported empathy did not moderate the impact of dictator offer on compensation behaviour, providing no support for Leliveld et al. (2012; Study 1); that is, more empathetic individuals did not provide greater compensation in response to less equal dictators offers.

Table 2

First order correlations $(N=460)$

\begin{tabular}{lccccc} 
& $\mathbf{1}$ & $\mathbf{2}$ & $\mathbf{3}$ & $\mathbf{4}$ & $\mathbf{5}$ \\
\hline 1. Gender $(0=$ male, $1=$ female $)$ & - & -.01 & -.02 & $.20 * * *$ & $.31 * * *$ \\
2. Dictator offer & & - & $.54 * * *$ & $-.14 * *$ & .03 \\
3. Perceived fairness & & & - & $-.20 * * *$ & -.01 \\
4. Compensation & & & - & $.22 * * *$ \\
5. Empathy & & & & - \\
\hline Note. ${ }^{* *} p<.01, * * * p<.001$ & & & &
\end{tabular}

Table 3

Mean and standard deviation in parenthesis of perceived fairness and compensation in response to the six dictator offer conditions

\section{Dictator offer N Perceived fairness a Compensation ${ }^{b}$}




\begin{tabular}{rrrr}
$\mathbf{0} \times 10 p$ & 69 & $2.65(1.03)$ & $1.70(1.15)$ \\
$\mathbf{1 0} \times \mathbf{1 0 p}$ & 70 & $3.06(1.20)$ & $1.24(1.29)$ \\
$\mathbf{2 0} \times \mathbf{1 0 p}$ & 81 & $3.23(1.00)$ & $1.30(1.38)$ \\
$\mathbf{3 0} \times \mathbf{1 0 p}$ & 83 & $3.46(1.23)$ & $.99(1.19)$ \\
$\mathbf{4 0} \times \mathbf{1 0 p}$ & 81 & $4.05(1.09)$ & $.99(1.11)$ \\
$\mathbf{5 0} \times \mathbf{1 0 p}$ & 81 & $5.17(1.43)$ & $1.16(1.40)$ \\
\hline
\end{tabular}

Note. $\mathrm{a}=$ scale $1-7 ; \mathrm{b}=$ scale $0-5$

Empathy as a Moderator of Dictator Offer-Fairness link. Second, our primary hypothesis (see Figure 1b) was tested in a moderated mediation using PROCESS Model 7 (Hayes, 2012) with 10,000 bootstrapped samples. Compensation was entered as the outcome variable, dictator offer as the predictor variable, perceived fairness as the mediator and empathy as the moderator of the relationship between dictator offer and perceived fairness (see Figure 2). Gender as a covariate was not a significant predictor of perceived fairness, $b=.05$, se $=.12, p=.671$, but it predicted compensation behaviour such that females compensated the victims with more coins than males, $b=.50$, se $=.11, p$ $<.001,95 \%$ CI $[.28, .73]$.

Dictator offer did not directly predict compensation, $b=-.03$, se $=.04, p=.397$ nor perceived fairness $b=-.28$, se $=.17, p=.104$. However, perceived fairness was related to compensation; the fairer the dictator offer was perceived to be, the lower the compensation rate was, $b=-.15$, se $=.05, p$ $=.002,95 \%$ CI $[-.24,-.06]$. Higher empathy, in turn, was associated with lower perceived fairness $b=$ -.43 , se $=.11, p<.001,95 \%$ CI [-.65, -.21]. This was further qualified by an interaction with dictator offer, $b=.15$, se $=.03, p<.001,95 \%$ CI [-.08, -.22]. Simple slopes analysis revealed that higher empathy was associated with a stronger positive relationship between dictator offer and perceived fairness, $b=.60$, se $=.05, p<.001,95 \%$ CI $[.51, .69]$ (see Figure 3). When empathy was lower, the relationship remained positive, but the strength of the effect was significantly weaker, $b=.32$, se $=$ $.05, p<.001,95 \%$ CI $[.23, .41]$. In other words, adolescents higher in empathy were more likely to perceive lower dictator offer (or the more unequal, qualified as 1 SD below the mean) as more unfair than their peers lower in empathy, but they were also more likely to perceive higher dictator offer (or the less unequal, qualified as $1 \mathrm{SD}$ above the mean) as more fair than their lower empathy counterparts. The overall moderated mediation model was significant, $b=-.02$, se $=.01,95 \%$ CI $[-.05$, 
-.01], suggesting that perceived fairness mediates the link from dictator offer to compensation behaviour; the relationship between dictator offer and fairness, in turn, is moderated by empathy.

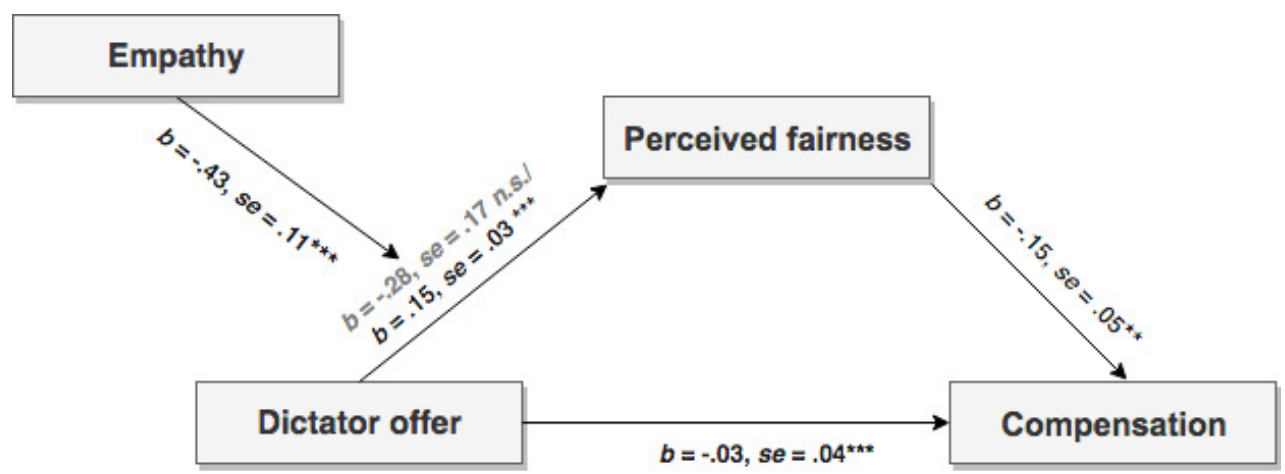

Figure 2. Moderated mediation model for compensation behaviour in the context of the dictator resource distribution. Unstandardised coefficients and standard errors are displayed. Gender was entered as a covariate of both perceived fairness and compensation, but it is not illustrated in the figure for clarity.

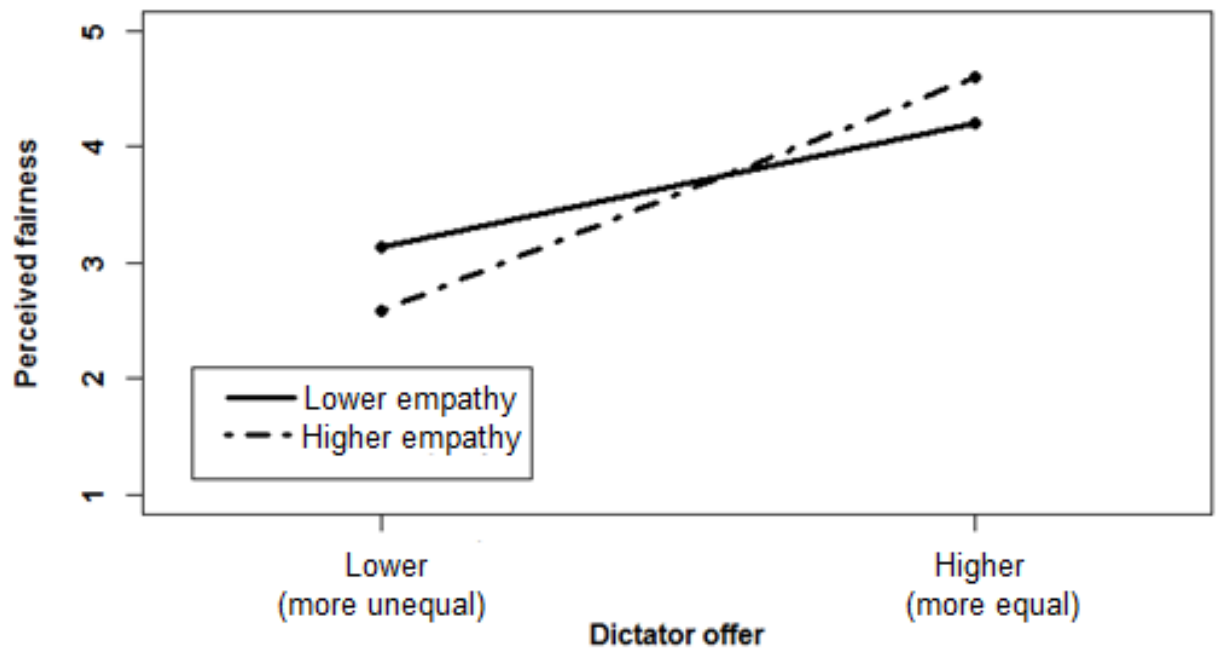

Figure 3. Perceived fairness of more unequal (1 SD below the mean) and more equal (1 SD above the mean) dictator offers, moderated by lower and higher empathy levels. 
Sensitivity Power Analysis. To evaluate whether the design of Study 1 was adequate to detect even small effect sizes, we conducted a sensitivity power analysis. Given the complexity of the design, the analysis was conducted based on the main moderation pathway of empathy on the relationship between dictator offer and perceived fairness. The analysis was conducted in G*Power (Faul, Erdfelder, Lang, \& Buchner, 2007) using the linear multiple regression method. The minimum effect size detectable in the present design at $80 \%$ power, alpha $=.05, \mathrm{~N}=466$ and with three predictors (dictator offer, empathy and the interaction between the two) was Cohen's $\mathrm{f}^{2}=.02$ demonstrating that our sample was sufficient to detect small effect sizes.

\section{Discussion}

Our findings offer initial evidence that the more one empathises with how the victim might feel, the higher the perception of injustice when distributions are less equal (lower dictator offers). This sense of injustice for highly empathetic participants relates to greater motivation to act against the injustice. In contrast to Leliveld et al.'s (2012; Study 1) which found that empathy shapes compensation behaviour but not judgements of fairness, the present study shows the opposite pattern whereby empathy acts as a moderator for fairness perceptions but not compensation behaviour.

Findings from Study 1 therefore, support the notion that empathy and fairness are linked, which has important implications for encouraging people to reduce inequality. Observing inequality itself is not sufficient to act prosocially; mechanisms underlying how people go from witnessing inequality to taking action against it need to be theoretically expanded. One way which empathy might influence fairness perceptions is via emotions. We propose that those with a stronger ability to understand someone else's emotions may be more likely to reflect on the victim's experience and thus, perceive the fairness of the decisions more in line with the victim and less like an unaffected third party. This theorising is aligned with Cialdini et al. (1997) who posited that the self of an observer may become more closely linked to the self of the victim; this observer would then interpret the situation as if it happened to them. In this vein, higher empathisers should more readily identify such emotions, which would deepen perceptions of unfairness in the case of unequal distributions. 
Evidence demonstrates that experiences of unfairness are associated with a wide range of emotions (Cohen-Charash \& Byrne, 2008). We focus specifically on anger as there is systematic evidence linking it to unfavourable outcomes and unfair procedures (Mikula, Scherer, \& Athenstaedt, 1998; Weiss, Suckow, \& Cropanzano, 1999). Previous research shows that observing others feeling angry can trigger a feeling of unfairness without any objective information on the source of anger (van Kleef, 2009). And, whilst anger is typically portrayed as a negative emotion associated with a range of antisocial behaviours and aggression (e.g., Berkowitz, 1990), it can also motivate others to restore equality (Gromet \& Darley, 2009; Lotz, Okimoto, Schlösser, \& Fetchenhauer, 2011). Anger also tends to be triggered by events that are inflicted by another person intentionally (Smith, Haynes, Lazarus, \& Pope, 1993). While other emotions, such as sadness, happiness (Tan \& Forgas, 2010) and guilt (Baumeister, Stillwell, \& Heatherton, 1994), can also be associated with perceptions of (un)fairness and wrongdoing, these emotions are not action-oriented in the way that anger is (Carver \& HarmonJones, 2009). In the context of an unfair condition in the dictator game, the dictator chooses to distribute the resources unequally, enabling feelings of anger in the observer on behalf of the victim. Feeling higher levels of empathy towards the victim of inequality, therefore, may evoke feelings of anger, which in turn, will be associated with higher perceptions of unfairness. Compared to the highempathy counterparts, those who are detached from the feelings of the victim would not experience an increase in anger and thus, the inequality may be judged as more fair. We hypothesise, then, that feelings of anger precede perceptions of fairness; only those who empathise with the victim would be able to share an understanding of the emotions associated with inequality. These feelings, in turn, would shape the observers' evaluations of the extent to which the distributions were fair or not. In other words, we argue that understanding of victim's emotions is what drives perceptions of unfairness among high empathisers.

Findings from Study 1 provide an important insight into the role of perceived fairness on resource distributions. Our work, however, has some limitations. First, the measure of empathy was self-reported with the alpha value falling slightly below the acceptable .70 level, potentially increasing measurement error. Second, our correlational assessment of empathy does not allow for establishing 
causation. Third, whilst we found a link between resource distribution and perceived fairness, we did not examine factors such as emotions, which may underlie this relationship. The aim of the preregistered Study 2, therefore, was to provide further support for our primary hypothesis that empathy shapes people's perceived fairness regarding resource distribution. To strengthen this evidence, we experimentally manipulated empathy. Moreover, we propose that empathy with the victim relates to understanding their emotions; therefore, we tested if anger is the mechanism through which individuals who empathise with others perceive more unfairness in contexts of inequality.

\section{Study 2: Pre-registered Study}

In line with Study 1, our primary hypothesis was that there will be a significant interaction between dictator offer and experimentally-manipulated empathy on perceived fairness. Compared to the low-empathy condition, we predicted that those in the high-empathy condition will rate the unequal dictator offer as less fair and the equal dictator offer as more fair. While the unequal dictator offer could be perceived as causing harm to the victim and be related to appraising the situation as morally wrong (see Schein \& Gray, 2017), we expected that the hypothesised interaction will be sustained even when controlling for perceived harm. While it is plausible that by emphasising with the victim of inequality may increase the degree to which harm was perceived, we did not expect perceptions of harm to diminish the effect on perceptions of fairness. We also aimed to test the interaction between the dictator offer and empathy as shown by Leliveld et al. (2012, Study 1), while controlling for the effect of perceived fairness. Our secondary hypothesis was that anger will mediate the impact of the interaction between dictator offer and empathy on perceived fairness. That is, extending Study 1, we argue that by empathising with the victim, the third party (the participant) will more readily experience emotions, specifically anger, on the victim's behalf in the case of unequal distributions. In other words, we propose that anger explains why higher empathy may be associated with lower perceptions of fairness in the context of inequality, as opposed to perceptions of unfairness leading to anger. We argue that other emotions such as sadness, guilt, or happiness will not be responsible for this mechanism, given anger's approach-motivated profile and its relation to the experience of unfairness. 


\section{Method}

\section{Participants}

Participants were recruited from Prolific Academic, an online participant recruitment tool, and paid $£ 0.60$ (equal to $€ 0.68$ ) for eight minutes of their time with a bonus of $£ 1$ paid at the end of the session regardless of the decision to compensate or not. This additional $£ 1$ was related to the number of coins participants received to play the game (50 coins worth 2 pence each). Prolific Academic was selected as it tends to produce high quality and reliable data (Peer, Samat, Brandimarte, \& Acquisti, 2017). The study was hosted online via Qualtrics (see supplementary materials for the questionnaire layout). There were no specific inclusion or exclusion criteria. In terms of the sample size required to detect the hypothesised effect, we focused our estimates on the primary hypothesis. The effect size of interaction dictator offer and empathy on perceived fairness in the non-registered Study 1 was small (partial $\mathrm{n}^{2}=0.03$ ). Therefore, the a-priori power analysis calculated using $\mathrm{G}^{*}$ Power (Faul et al., 2007) suggests that a sample of $\mathrm{N}=342$ was needed to obtain this effect in a 2 (dictator offer) $\mathrm{x} 2$ (empathy) design with a one covariate (gender) at $90 \%$ power and alpha level of 0.05 . With an introduction of additional controls, we aimed to recruit extra 15 participants per cell, increasing the final sample to 402 participants. In total, 406 (60\% male, 40\% female) participants aged between 18 and 74 years old $(M=31.91, S D=11.14)$ completed the study.

\section{Procedure and Materials}

The order is which elements of the study are described below corresponds to the running order of the study (see Figure 4).

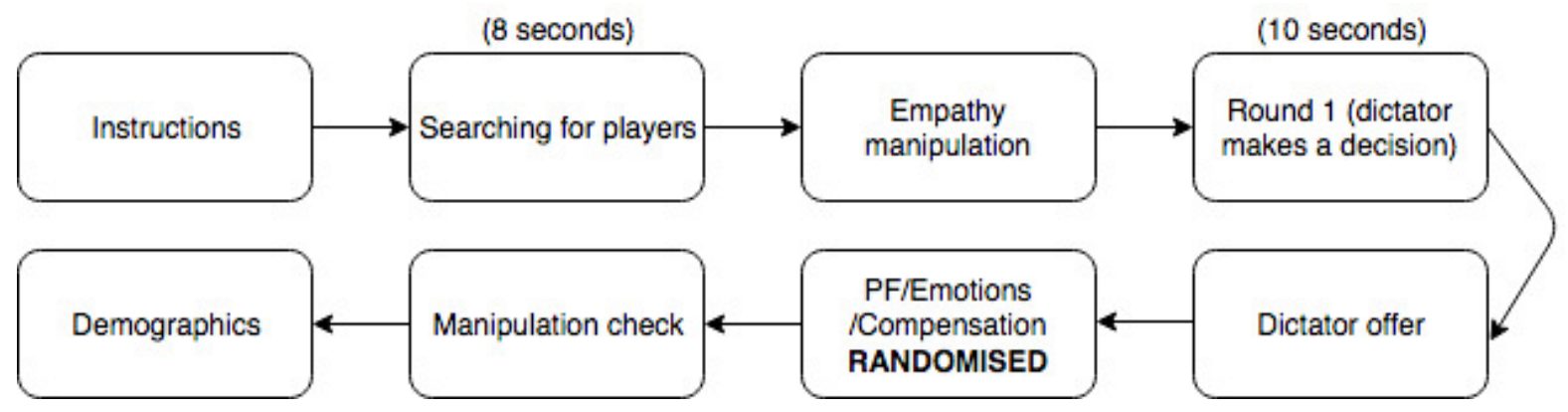

Figure 4. Running order of Study 2. $\mathrm{PF}=$ perceived fairness and harm. 
Empathy Manipulation. Participants were randomly assigned to either a low-empathy or high-empathy condition following the procedures used by Batson et al. (2002). For participants in the low-empathy condition, the instructions read as follows: "While you are playing this game, try to take an objective perspective toward what is happening. Try not to get caught up in how any player feels; just remain objective and detached." For participants in the high-empathy condition, the instructions read as follows: "While you are playing the game, try to imagine how Player B feels about the outcomes they receive. Try to feel the full impact of what they may think and how they feel as a result." Previous research has found this type of empathy manipulation to produce large effect sizes both in laboratory based and online studies (Batson et al., 2002; Berenguer, 2007; Faulkner, 2018; Oceja et al., 2014).

The Game. To increase participants' engagement in the game, before the game commenced, participants were shown a screen with the message 'Searching for other players' along with an animated buffering symbol for eight seconds. Following this, the screen changed to 'All players are ready. Please press 'continue' to begin the game'. To reduce the number of between-subjects conditions from the non-registered Study 1, in Round 1 participants were assigned to one of two (as opposed to six) dictator offer conditions whereby Player A (the dictator) shares coins unequally (giving 20 of their 100 coins) or equally (giving 50 out of 100 coins) with Player $\mathrm{B}^{2}$. Round 1 was also programmed so that Player A took ten seconds to make their decision, after which the screen automatically changed. As in Study 1, at the completion of the study, all participants were compensated the same amount regardless of their choice to compensate or not to avoid punishing those who chose to use their share of allocated coins.

The following three components were presented in random order to avoid potential order effects.

\footnotetext{
${ }^{2}$ Note that in Leliveld et al. (2012, Study 2) participants saw only the unequal condition.
} 
Perceived Fairness and Perceived Harm. We measured participants' reaction to the dictator offer in Round 1. They rated how fair, just, and appropriate the dictator offer was. Perceived fairness was calculated by deriving the mean score of the three items with a higher score indicating higher perceived fairness $(\alpha=.91)$. This section also asked participants to judge the extent to which the dictator offer was harmful $(1=$ not at all; $7=$ very much $)$. All items were randomly displayed.

Emotions. Participants also rated the degree to which they felt a range of emotions in relation to the dictator offer on a seven-point scale $(1=$ not at all; $7=$ very much $)$. Although we were primarily interested in anger, we asked about a number of additional emotions as a concealment, including asking if participants felt sad, guilty, and happiness in response to the dictator offer. All emotions were randomly displayed.

Round 2 Compensation. In Round 2, participants were given 50 coins worth 2 pence each. Following Leliveld et al.'s Study 2, participants were told that they could either compensate Player B by transferring some of their coins or keep all the coins (worth £1) for themselves. The following message was displayed: 'You can give Player B between 1 and 50 coins and the appropriate amount will be taken away from your bonus pay of $£ 1.00$. If you decide to keep all the coins to yourself, you will be paid bonus pay of $£ 1.00$ in addition to the $£ 0.60$ awarded for participation'.

Manipulation Check. Following the three previous components, participants were then presented with an empathy manipulation check previously utilised by Batson et al. (2002). Participants were asked to indicate "While playing the game, to what extent did you concentrate on being objective?" and "To what extent did you concentrate on Player B's feelings?" ( 1 = not at all, 7 = very much). The first item was reversed-scored and the two items were combined into a composite "empathy manipulation check" score with a higher score reflecting greater empathy. As a further manipulation check, participants were asked "To what extent do you think Player B experienced anger in this game?" (1 = not at all; 7 = very much). This was to validate whether those in high-empathy condition inferred higher anger from the victim than those in low-empathy condition item ("inferred anger manipulation check"). Each manipulation check item was displayed on a new page and the order was randomised. 
Demographic Measures. At the end of the experiment, we collected information on participants' gender and age.

\section{Results}

For description of planned analyses, see preregistration: https://osf.io/mgexp/. Data and analysis code are available via the Open Science Framework project page: https://osf.io/83v4u. Crosscorrelations and descriptive statistics are reported in Tables 4 and 5. 
Table 4

Bivariate correlations in Study $2(N=406)$

\begin{tabular}{|c|c|c|c|c|c|c|c|c|c|c|}
\hline & 1 & 2 & 3 & 4 & & 5 & 6 & 7 & 8 & 9 \\
\hline 1. Gender & - & .08 & .08 & -.07 & & .03 & -.10 & $-.15 *$ & -.06 & -.13 \\
\hline 2. Dictator offer & .09 & - & $.51 * * *$ & .02 & & .13 & -.13 & $-.21 * *$ & -.11 & $.29 * * *$ \\
\hline 3. Perceived fairness & .05 & $.62 * * *$ & - & -.24 & $* * *$ & $.16 *$ & $-.24 * * *$ & $-.26 * * *$ & $-.14 *$ & $.56 * * *$ \\
\hline 4. Perceived harm & -.06 & $-.33 * * *$ & $-.41 * * *$ & - & & .03 & $.19 * *$ & $.22 * *$ & $.17 *$ & -.10 \\
\hline 5. Compensation & -.09 & .07 & $<.01$ & .03 & & - & -.01 & $<-.01$ & -.06 & $.28 * * *$ \\
\hline 6. Angry & -.11 & $-.41 * * *$ & $-.50 * * *$ & .51 & $* * *$ & .03 & - & $.67 * * *$ & $.54 * * *$ & -.08 \\
\hline 7. Sad & -.05 & $-.42 * * *$ & $-.47 * * *$ & .50 & $* * *$ & .06 & $.74 * * *$ & - & $.57 * * *$ & -.08 \\
\hline 8. Guilty & -.05 & $-.20 * *$ & $-.25 * * *$ & .31 & $* * *$ & $-.16 *$ & $.42 * * *$ & $.32 * * *$ & - & .08 \\
\hline 9. Нарру & .03 & $.43 * * *$ & $.56 * * *$ & -.27 & $* * *$ & .01 & $.32 * * *$ & $-.36 * * *$ & -.08 & - \\
\hline
\end{tabular}

Note. $* p<.05, * * p<.01, * * * p<.001$. Values for the high-empathy condition are below the diagonal and the low-empathy condition values are above. Gender was coded $1=$ male, $2=$ female and dictator offer was coded $0=$ unequal offer, $1=$ equal offer 
Table 5

Mean and standard deviation in parenthesis of the key measured variables in response to the unequal and equal dictator offers across low- and high-empathy conditions

\begin{tabular}{llcccc} 
Dictator offer & Empathy & Perceived fairness & Perceived harm & Compensation & Anger \\
\hline \multirow{2}{*}{ Unequal } & Low & $4.07(1.24)$ & $2.11(1.33)$ & $12.60(10.60)$ & $1.91(1.32)$ \\
& High & $3.81(1.29)$ & $2.53(1.60)$ & $15.80(11.50)$ & $2.48(1.61)$ \\
\multirow{2}{*}{ Equal } & Low & $5.57(1.28)$ & $2.17(1.74)$ & $16.20(14.90)$ & $1.58(1.19)$ \\
& High & $5.78(1.24)$ & $1.55(1.10)$ & $17.60(15.30)$ & $1.31(.82)$ \\
\hline
\end{tabular}

\section{Manipulation Check}

Contrary to our expectations and Baston et al.'s (2002) previous research, the two empathy manipulation check items, being objective and concentrating on Player B's feelings, were not related to one another, $r(404)=-.09, p=.066$. Given this, we deviated from the original analysis plan to combine these items, and instead entered them separately into the 2 (Dictator Offer: 20 vs 50) x 2 (Empathy Condition: low vs high) between groups ANOVA analysis. For both items, there was no main effect of dictator offer [objectivity: $F(1,404)=.04, p=.846, \eta_{\mathrm{p}}{ }^{2}<.01$; concentration on feelings: $\left.F(1,404)=2.09, p=.149, \eta_{\mathrm{p}}{ }^{2}=.01\right]$. In the high-empathy condition, participants were more likely to report that they concentrated on Player B's emotions during the game $(M=2.96, S D=1.85)$ compared to those in low-empathy condition $(M=4.94, S D=1.76), F(1,404)=122.02, p<.001, \eta_{\mathrm{p}}{ }^{2}=.23$. However, when comparing across empathy conditions, participants did not differ in their reported levels of objectivity in the game, $F(1,404)=1.73, p=.189, \eta_{\mathrm{p}}{ }^{2}<.01$.

In the same ANOVA model, we included inferred anger to verify whether participants in the high-empathy condition were more likely to infer anger from Player B than those in the low-empathy condition. There was a significant interaction of Dictator Offer $\mathrm{x}$ Empathy on inferred anger, $F(1,401)$ $=4.18, p=.042, \eta_{\mathrm{p}}^{2}=.01$. That is, participants in the low-empathy condition who observed an unequal offer perceived Player B to experience the same level of anger as those who observed an equal offer, $t(201)=1.69, p=.092, d=.24$. In the high-empathy condition, however, participants who observed an 
unequal offer inferred more anger from Player B $(M=3.67, S D=1.73)$ than those who observed an equal dictator offer $(M=2.52, S D=1.82), t(201)=4.62, p<.001, d=.65$.

These analyses suggest that while participants in the high-empathy condition reported to concentrate more on Player's B emotions than participants in the low-empathy condition, they did not report staying more objective. The self-reported focus on Player's B findings was further demonstrated by the finding that participants in the low-empathy condition did not infer more anger from Player B in unequal and equal dictator offer conditions, while those in the high-empathy condition judged Player B to experience more anger in the unequal offer condition. While not meeting our expectations in full, the difference in reported concentration on Player B's feelings offers some support for our empathy manipulation and allows for proceeding to the subsequent analyses.

\section{Perceived Fairness}

To evaluate the effect of the Dictator Offer $\mathrm{x}$ Empathy interaction on perceived fairness, another ANOVA test was conducted, controlling for the effects of gender. Gender as a covariate was a non-significant predictor of perceived fairness, $F(1,405)=3.44, p=.064, \eta_{\mathrm{p}}{ }^{2}=.01$. Dictator offers that were unequal $(M=3.93, S D=1.27)$ were perceived as significantly more unfair than those that were equal $(M=5.67, S D=1.26), F(1,405)=191.84, p<.001, \eta_{\mathrm{p}}{ }^{2}=.33$, while the main effect of the empathy condition was non-significant, $F(1,405)=.07, p=.794, \eta_{\mathrm{p}}{ }^{2}<.01$. The hypothesised Dictator Offer $x$ Empathy on perceived fairness interaction was significant, $F(1,405)=4.08, p=.044, \eta_{\mathrm{p}}{ }^{2}=.01$. The direction of the interaction effect was identical to that reported in Study 1, however, post-hoc ttests revealed a non-significant effect of the empathy condition on perceived fairness in both unequal, $t(201)=1.45, p=.149, d=.20$, and equal dictator offer conditions, $t(201)=-1.19, p=.234, d=.17$. Thus, while the interaction was significant, we did not replicate its previously reported effect size. Furthermore, when controlling for perceptions of fairness in the model, Dictator Offer x Empathy interaction on perceived fairness was non-significant, $F(1,405)=1.05, p=.306, \eta_{\mathrm{p}}{ }^{2}<.01$.

\section{Compensation Behaviour}


Next, we proceeded with testing whether the Dictator Offer x Empathy interaction had a significant effect on compensation behaviour (the number of coins given). In contrast to Study 1, participants in the equal dictator offer condition compensated at a higher rate $(M=16.83, S D=15.10)$ than those in the unequal dictator offer condition $(M=14.35, S D=11.21), F(1,405)=4.06, p=.045$, $\eta_{\mathrm{p}}{ }^{2}=.01$. The main effect of empathy, $F(1,405)=3.19, p=.075, \eta_{\mathrm{p}}{ }^{2}=.01$, and the Dictator Offer $\mathrm{x}$ Empathy interaction, $F(1,405)=.52, p=.472, \eta_{\mathrm{p}}^{2}<.01$, however, were non-significant. When perceived fairness was added as a covariate in the model, it was not related to compensation behaviour, $F(1,405)=.31, p=.580, \eta_{\mathrm{p}}{ }^{2}<.01$, and thus, it did not alter the pattern of results with all main and interaction effects remaining non-significant. Therefore, the measures employed in the present study could not reliably predict compensation behaviour, contrary to previous research utilising dictator games.

\section{The Role of Experienced Anger}

Following the test of the Dictator Offer $x$ Empathy interaction on perceived fairness, we proceeded with testing our hypothesis on whether experienced anger can explain the effect of empathy across dictator offer conditions on perceived fairness. We entered our variables of interest into a moderated mediation model using Hayes' (2007) PROCESS Model 7 with 10,000 bootstrap samples and gender as a covariate. Gender as a covariate was not a significant predictor of perceived fairness, $b$ $=.13, s e=.12, p=.267$, but it predicted experienced anger such that males reported higher levels of anger than females, $b=-.32$, se $=.12, p=.013,95 \%$ CI $[-.58, .07]$.

Equal (versus unequal) dictator offer directly predicted higher levels of perceived fairness, $b=$ $1.53, s e=.12, p<.001,95 \%$ CI $[1.28,1.78]$, but not experienced anger, $b=-.31, s e=.18, p=.087$. Higher experience of anger, however, was strongly related to lower perceptions of fairness, $b=-.28$, $s e=.05, p<.001,95 \%$ CI [-.37, -.18]. Participants in the high-empathy (versus low-empathy) condition reported higher anger $b=.61, s e=.18, p=.001,95 \% \mathrm{CI}[.25, .97]$. This main effect of empathy condition was further qualified by an interaction with dictator offer, $b=-.89$, se $=.25, p$ 
$<.001,95 \% \mathrm{CI}[-1.39,-.39]^{3}$. Figure 5 shows a boxplot distribution of experienced anger scores across dictator offer and empathy conditions. We employed simple slope analysis to verify the nature of this interaction.

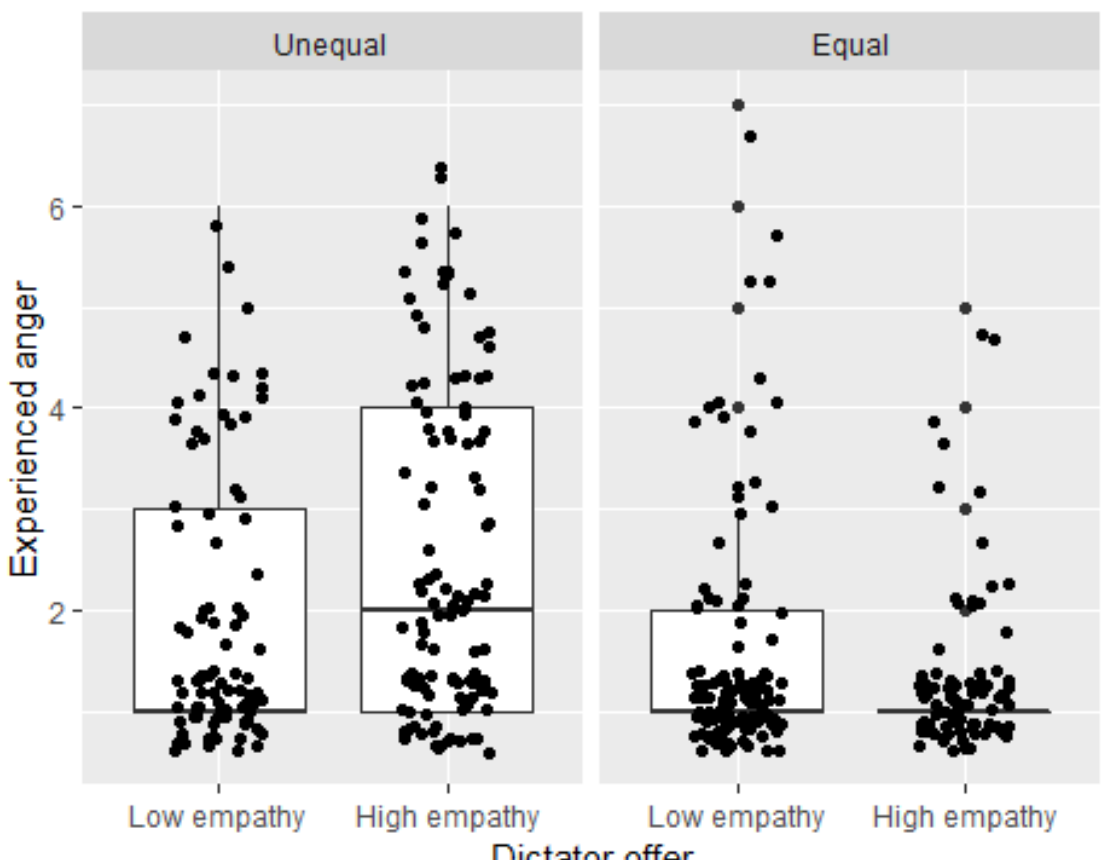

Figure 5. Experienced anger in unequal and more equal dictator offers in low and high empathy conditions. Those empathising with the victim experienced anger when the dictator's distribution was unequal.

In the high-empathy condition, there was a stronger relationship between dictator offer and feelings of anger; namely, the unequal dictator offer caused higher experiences of anger than the equal dictator offer, $b=-1.20$, se $=.18, p<.001,95 \%$ CI $[-1.55,-.84]$. In the low-empathy condition, the link between dictator offer and experience of anger was non-significant, $b=-.31$, se $=.18, p=.087$, suggesting that participants in that condition were not more angered by the unequal offer than those who were shown an equal offer. Breaking down the interaction to compare participants in unequal and equal dictator offer conditions, the difference between participants in the low- and high-empathy conditions was non-significant when the dictator offer was equal, $b=-.28$, se $=.18, p=.115$. However,

\footnotetext{
${ }^{3}$ In exploratory analyses, we also included perceived harm as a covariate. This interaction remained significant, $b=-.61, s e=.24, p=.014,95 \%$ CI $[-1.09,-.12]$.
} 
when the dictator offer was unequal, participants in the high-empathy condition experienced more anger than participants in low-empathy condition, $b=.61$, $s e=.18, p=.001,95 \% \mathrm{CI}[.25, .96]$.

The overall moderated mediation model was significant, $b=.25$, se $=.09,95 \%$ CI [.10, .44], suggesting that anger mediates the link from dictator offer to perceived fairness; the relationship between dictator offer and anger, in turn, is moderated by empathy (see Figure 6). This pattern resembles the results reported in Study 1 relating to perceived fairness as the lowest levels of fairness were reported by high empathisers in the unequal dictator condition and the highest levels of anger in Study 2. Therefore, the Dictator Offer x Empathy interaction on perceived fairness is an indirect one, fully mediated by increased feelings of anger.

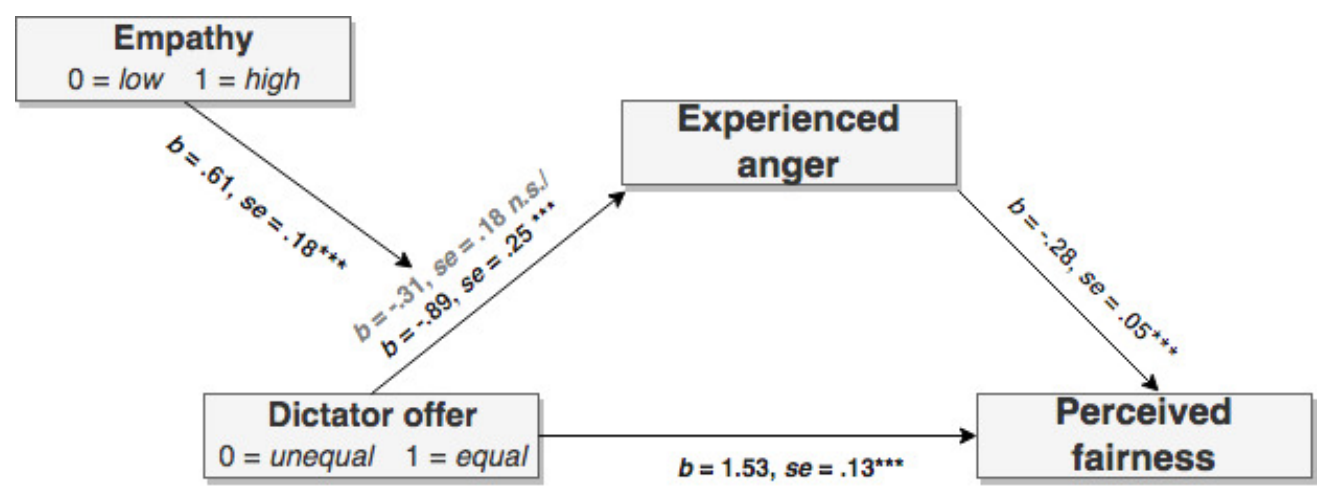

Figure 6. Moderated mediation model for perceived fairness in the context of the dictator resource distribution. Empathising with the victim in context of unequal offer is associated with higher anger, which predicts lower perceptions of fairness. Unstandardised coefficients and standard errors are displayed. Gender was entered as a covariate of both experienced anger and perceived fairness, but it is not illustrated in the figure for clarity.

\section{Anger or Other Emotions?}

Finally, we examined whether anger is a unique emotion experienced in contexts of inequality for those in the high-empathy condition by comparing anger effects with other emotions. To test this assertion, self-reported anger, sadness, guilt, and happiness were entered as outcome variables into a 2 (Dictator Offer: 20 vs 50) x 2 (Empathy Condition: low vs high) between groups ANOVA analysis. 
While the levels of these emotions did not differ across empathy conditions, $F(1,405)<3.18, p>$ $.075, \eta_{\mathrm{p}}{ }^{2}>.01$, participants reported different emotions depending on whether they observed an unfair or an equal distribution. Specifically, participants observing an unequal dictator offer reported higher anger, sadness and guilt, as well as lower levels of happiness, than those observing the equal dictator offer. As reported earlier, there was an interaction between dictator offer and empathy was observed in the case of anger, $F(1,405)=12.21, p=.001, \eta_{\mathrm{p}}{ }^{2}=.03$, and also an interaction for sadness, $F(1,405)=$ $8.06, p=.005, \eta_{\mathrm{p}}{ }^{2}=.02$, but not for any of the other emotions.

\section{Exploratory Analyses}

The Role of Sadness. As we did not expect a significant interaction between Dictator Offer and the Empathy Condition on experienced sadness, we probed this effect to uncover its nature. When the dictator offer was equal, participants across the low- and high-empathy conditions did not differ in their levels of sadness, $t(199.210)=.98, p=.328, d=.18$. When the dictator offer was unequal, however, participants in the high-empathy condition reported experiencing higher levels of sadness $(M$ $=2.76, S D=1.68)$ than those in the low-empathy condition $(M=2.19, S D=1.68), t(200.42)=2.55, p$ $=.011, d=.36$, mirroring the results on experienced anger.

Given that perceived harm was a relevant variable in the Dictator Offer x Empathy interaction on perceived fairness, we re-analysed the effect of this interaction on all emotions, entering perceived harm as a covariate. After controlling for perceived harm, the interaction of Dictator Offer x Empathy on sadness was no longer significant, $F(1,405)=3.08, p=.080, \eta_{\mathrm{p}}{ }^{2}=.01$, but it remained significant for anger, $F(1,405)=6.05, p=.014, \eta_{\mathrm{p}}{ }^{2}=.02$. Thus, anger, more than any other emotions appeared to account for the effect of empathising with the victims of inequality.

Other Predictors of Compensation Behaviour. Given that dictator offer, empathy and perceived fairness did not influence compensation behaviour, we explored whether compensation behaviour was related to any of the manipulation check items. While there was no relationship between staying objective and compensation behaviour $r(405)=-.03, p=.604$, higher levels of 
compensations were related to greater concentration on Player B's feelings, $r(404)=.36, p<.001$ and lower inferred anger from Player B, $r(405)=-.34, p<.001$.

\section{Discussion}

The findings of our pre-registered Study 2 provide further evidence that in contexts of inequality, empathy may be the key mechanism through which people experience anger on behalf of the victim, which in turn shapes perceptions of fairness. The results show that those in the highempathy condition not only experienced more anger for the victim of inequality, but they also inferred more anger from the victim compared to those in the low-empathy condition. Higher experienced anger, in turn, was related to lower perceptions of fairness. These findings suggest that empathy enables experiencing emotions on behalf of the victim of inequality and that anger is strongly related to perceptions of fairness. In contrast to our expectations, levels of compensation were not significantly different across empathy conditions, nor they were related to perceived fairness in this study, in contrast to Study 1. Exploratory evidence linked higher levels of compensation to reporting the self-reported concentration on their feelings, but contrary to one would assume, participants compensated more when they inferred that Player B experienced less anger. Given that these analyses were post-hoc, we are not sure why inferring more anger felt by Player B would necessarily be related to lower compensation across all experimental conditions.

We were unable to replicate compensation patterns based on the experimental conditions, in contrast to Leliveld et al. (2012) and other literature in this area (Fehr \& Gächter, 2002; Weng et al., 2015; Will et al., 2013). Although we did not necessarily expect experimental conditions to influence compensation behaviour after controlling for perceived fairness, our findings demonstrate that compensation behaviour was not significantly related to perceived fairness. In other words, perceiving the dictator offer to be unfair did not motivate people to compensate the victim, even if in the highempathy condition where participants reported paying attention to victim's feelings more than those in the low-empathy condition. There are many reasons why this may be the case. The dictator game, although being conducted online, had a high validity as it disguised the experiment as a game between 
other participants. The potential problem, however, could have been that the stakes were relatively high for the participants to act in self-serving ways as they could earn almost double of their base payment. Despite assessing the unequal dictator offer to be significantly more unfair that the equal dictator offer, people were not necessarily more likely to compensate victims of inequality at a higher level. This suggests that appraisal processes and action to restore inequality were not connected in the current study. The size of the stake can certainly be an important factor; this may need further investigation as most of the research using dictator games points to clear links between dictator offer and compensation behaviours (see Amir, Rand, \& Gal, 2012). It is also possible that given the option, participants could have restored inequality, for example, by punishing the dictator (e.g., Fehr \& Gächter, 2002; Gromet \& Darley, 2009; Lu \& McKeown, 2018), something that was not addressed in the present research.

\section{General discussion}

Building on the work by Leliveld et al. (2012), the present research aimed to examine the roles of fairness and empathy in predicting compensatory behaviours, even when this means forgoing selfinterest, in a dictator-style game. We argued that the way people arrive at their judgements regarding fairness is not universal, but that it is shaped by empathy. We found initial support for this hypothesis in the non-registered Study 1 where it was shown that higher empathy was related to lower levels of perceived fairness in unequal distributions, which in turn was associated with how likely the individuals compensated the victims of injustice. Pre-registered Study 2 partially replicated these findings and experimentally manipulated empathy. Firstly, although those who were in the high empathy condition did not directly perceive the dictator offer to be more unfair than those in the low empathy condition, they were more likely to experience anger on behalf of the victim, which was related to lower levels of perceived fairness. This indirect effect, even in the absence of the direct effect, generally provides a strong evidence for the hypothesis if it is theory driven as in the case of the present research (Rucker, Preacher, Tormala, \& Petty, 2011). Further to this, those in the highempathy condition who witnessed an unequal dictator offer in Study 2 more readily inferred that the 
victim felt angry and also experienced anger themselves when compared to those in the low-empathy condition.

Our research findings are in line with the work of Cialdini et al. (1997) who argued that empathy enables the self of an observer to become more closely linked to the self of the victim, allowing them to share emotions and allowing third-party individuals to interpret events as if it happened to them. Our research adds to this understanding, showing that by sharing anger, individuals are also more likely to shift their understanding of what is considered fair or unfair. Consequently, the present research supports the notion that perceptions of fairness are not objective (i.e., unequal distributions are not always unfair and equal distributions always fair) but are embedded in context (Platow et al., 2014; Radburn et al., 2016). This is in contrast with Study 1 by Leliveld et al. (2012) which suggested that empathy shapes the compensation behaviour, but not judgements of fairness. We argue that the more one can put themselves into another person's position, the more likely they are to perceive injustice through their eyes, which in turn may increase their motivation to act against the injustice. This contributes to research suggesting that people perceive fairness for self versus others distinctly (Lupfer et al., 2000; Messick et al., 1985) and to the literature examining the interplay between justice and empathy (Blader \& Tyler, 2002).

\section{Implications, Limitations, and Future Directions}

The present work has important implications for how people may be encouraged to stand up to injustices faced by others. Both the present research and that carried out by Leliveld et al. (2012) suggest that empathy is an important variable in reacting to inequality. Despite no consensus regarding whether empathy can trigger mechanisms towards compensating behaviour, the present research shows that empathising with others increases one's sensitivity to victim's emotions and by increasing one's levels of anger, and to some extent sadness, it can be the key mechanism explaining why there are divergences in whether inequalities are perceived to be fair or not. Appraising inequalities as unfair is the first step towards creating motivations to act against them. As such, providing people with empathy training may equip them with the necessary skills to civically engage and strive towards 
reducing inequality in the societies they live in, especially as there is evidence that such training is successful (Leiberg, Klimecki, \& Singer, 2011).

Despite these implications, there are some limitations of the present research. First, whilst an experimental design allows capturing of cause and effect, a dictator style game is arguably somewhat removed from the seriousness of injustices experienced in the real world. Indeed, not receiving a fair share of coins may not come close to real-life structural inequalities, but nonetheless it is a first step towards understanding what can motivate people to help others even at their own expense. For this reason, understanding the impact of stakes of reducing inequality at a cost to one's self is an important avenue of research that should be pursued to understand when perceived fairness leads to compensation behaviour.

Second, the empathy manipulation used in the pre-registered Study 2, whilst previously tested (Batson et al., 2002; Berenguer, 2007; Faulkner, 2018; Oceja et al., 2014) did not work as expected as participants in the current study who were in the low-empathy condition did not remain more objective in the game, compared to those in the high empathy condition, evidenced through the manipulation check. It may be that the manipulation did not necessarily prevent those in the low-empathy condition from empathising with the victim of inequality. Thus, while the partial replication of our previous results provides some assurance regarding the manipulation, these findings should be taken with caution.

Third, it is important to acknowledge that our hypothesised and tested model may not be the only model that explains individuals' evaluations of fairness. One could argue for a moral underpinning of this effect, given that perceived harm appeared to be a relevant factor in shaping perceived fairness. Or, perceived fairness could well be construed as preceding anger rather than being an outcome of anger. While empathy and inequality were both manipulated in Study 2, evidence regarding the role of anger on perceived fairness rests on mediation tests, limiting the ability to establish causality. Having said that, best practices recommendations regarding the use of mediation models were followed in the present research (see Fiedler, Harris, \& Schott, 2018). Namely, the role of experienced anger was theoretically grounded (and pre-registered) and we considered other 
mediation pathways via alternative emotions, permitting rigorous and comprehensive hypothesis testing.

An important extension of the dictator game methodology in this area of research, particularly contexts troubled by intergroup conflict, would be to address how empathy may affect perceptions of fairness in contexts of inequality across group boundaries. For example, under which circumstances could empathy enable individuals to feel anger on behalf of the outgroup member and thus, condemn the actions of the ingroup member in clear-cut contexts of inequality? Understanding these mechanisms is crucial for empowering people to be active citizens in their communities, calling out injustices, and mobilising themselves to overcome unjust inequalities.

In conclusion, the present research demonstrates that fairness is not necessarily a commonly agreed set of norms; instead, empathising with those in need allows individuals to experience their situation more deeply through the emotions they experience. Understanding that such circumstances produce feelings of anger allows third-party onlookers to perceive those circumstances as more unfair. Those who do not empathise, on the other hand, may not be plagued by the same sense of unfairness. These findings point to fairness as a dynamic concept as opposed to a passive one. Uncovering what strikes individuals as unfair is at the heart of making others more open to act in less selfish ways.

\section{Acknowledgements}

Study 1 was supported by the Richard Benjamin Trust and the British Academy (BA) / Leverhulme [SG 150807] awarded to the second and third authors. Study 2 was supported by the European Association of Social Psychology pre-registered grant awarded to the first author. Thank you to Jeffrey Hanna, Alexandra Kenny, Clarissa Courtney, Lauren Brown, Dean O’Driscoll, Marion Schulz, Lukas Horstmeier, Sofia Chirtoglou, and Yangjunru (Cecilia) Li for their support with data collection of Study 1 and to Delfina Bilello for reading an earlier version of this paper.

\section{References}

Amir, O., Rand, D. G., \& Gal, Y. K. (2012). Economic games on the internet: The effect of $\$ 1$ stakes. PLoS ONE, 7, 1-4. https://doi.org/10.1371/journal.pone.0031461 
Batson, C. D. (1991). The altruism question: Toward a social psychological answer. Hillsdale, NJ: Erlbaum.

Batson, C. D. (1998). Altruism and prosocial behavior. In D. T. Gilbert, S. T. Fiske, \& G. Lindzey (Eds.), The handbook of social psychology (4th ed., pp. 282-316). New York: McGraw-Hill.

Batson, C. D., Chang, J., Orr, R., \& Rowland, J. (2002). Empathy, attitudes, and action: Can feeling for a member of a stigmatized group motivate one to help the group? Personality and Social Psychology Bulletin, 28, 1656-1666. https://doi.org/10.1177/014616702237647

Berenguer, J. (2007). The effect of empathy in proenvironmental attitudes and behaviors. Environment and Behavior, 39, 269-283. https://doi.org/10.1177/0013916506292937

Berkowitz, L. (1990). On the formation and regulation of agner and aggression: A cognitiveneoassiationistic analysis. American Psychologist, 45, 494-503. https://doi.org/10.1037/0003066X.45.4.494

Blader, S. L., \& Tyler, T. R. (2002). Justice and empathy: What motivates people to help others? In The Justice Motive in Everyday Life (pp. 226-250). Cambridge, UK: Cambridge University Press.

Carver, C. S., \& Harmon-Jones, E. (2009). Anger is an approach-related affect: Evidence and implications. Psychological Bulletin, 135, 183-204. https://doi.org/10.1037/a0013965

Cialdini, R. B., Brown, S., Lewis, B., Luce, C., \& Neuberg, S. (1997). Reinterpreting the empathyaltruism relationship: When one into one equals oneness. Journal of Personality and Social Psychology, 73, 481-494. https://doi.org/10.1037//0022-3514.73.3.510

Cialdini, R. B., Schaller, M., Houlihan, D., Arps, K., Fultz, J., \& Beaman, A. L. (1987). Empathybased helping: Is it selflessly or selfishly motivated? Journal of Personality and Social Psychology, 52, 749-758. https://doi.org/10.1037/0022-3514.52.4.749

Cohen-Charash, Y., \& Byrne, Z. S. (2008). Affect and justice: Current knowledge and future directions. In M. Ashkanasy \& C. L. Cooper (Eds.), Research companion to emotions in 
organizations (pp. 360-391). Cheltenham, UK: Edward Elgar Publishing.

Coke, J. S., Batson, C. D., \& McDavis, K. (1978). Empathic mediation of helping: A two-stage model. Journal of Personality and Social Psychology, 36, 752-766. https://doi.org/10.1037/00223514.36.7.752

Davis, M. H. (1980). A mulitdimensional approach to individual differences in empathy. Journal of Personality and Social Psychology, 44, 113-126. https://doi.org/10.1037/0022-3514.44.1.113

Dunfield, K., Kuhlmeier, V. A., O’Connell, L., \& Kelley, E. (2011). Examining the Diversity of Prosocial Behavior: Helping, Sharing, and Comforting in Infancy. Infancy, 16, 227-247. https://doi.org/10.1111/j.1532-7078.2010.00041.x

Dunn, J., \& Munn, P. (1986). Siblings and the development of prosocial behaviour. International Journal of Behavioral Development, 9, 265-284. https://doi.org/10.1177/016502548600900301

Eagly, A. H., \& Crowley, M. (1986). Gender and helping behavior: A meta-analytic review of the social psychological literature. Psychological Bulletin, 100, 283-308. https://doi.org/10.1037/0033-2909.100.3.283

Eisenberg, N., \& Fabes, R. A. (1998). Prosocial development. In Handbook of child psychology: Vol. 3. Social, emotional, and personality development (pp. 701-778). New York, NY: Wiley.

Eisenberg, N., Miller, P. A., Shell, R., McNalley, S., \& Shea, C. (1991). Prosocial development in adolescence: A longitudinal study. Developmental Psychology, 27, 849-857. https://doi.org/10.1037/0012-1649.27.5.849

Eisenberg, N., \& Mussen, P. H. (1989). The roots of prosocial behavior in children. Cambridge, UK: Cambridge University Press.

Faul, F., Erdfelder, E., Lang, A., \& Buchner, A. (2007). G*Power 3: A flexible statistical power analysis program for the social, behavioural, and biomedical sciences. Behaviour Research Methods, 39, 175-191. https://doi.org/10.3758/BF03193146

Faulkner, N. (2018). "Put yourself in their shoes": Testing empathy's ability to motivate cosmopolitan 
behavior. Political Psychology, 39, 217-228. https://doi.org/10.1111/pops.12411

Fehr, E., \& Fischbacher, U. (2004). Third party punishment and social norms. Evolution and Human Behavior, 25, 63-87. https://doi.org/10.1016/S1090-5138(04)00005-4

Fehr, E., \& Gächter, S. (2002). Altruistic punishment in humans. Nature, 415, 137-140. https://doi.org/10.1038/415137a

Fiedler, K., Harris, C., \& Schott, M. (2018). Unwarranted inferences from statistical mediation tests An analysis of articles published in 2015. Journal of Experimental Social Psychology, 75, 95102.

Gromet, D. M., \& Darley, J. M. (2009). Punishment and beyond: Achieving justice through the satisfaction of multiple goals. Law and Society Review, 43, 1-38. https://doi.org/10.1111/j.15405893.2009.00365.x

Hayes, A. F. (2012). PROCESS: A versatile computational tool for observed variable mediation, moderation, and conditional process modeling. Retrieved from http://www.afhayes.com/

Hoffman, M. L. (2008). Empathy and prosocial behaviour. In M. Lewis, J. M. Haviland-Jones, \& L. Feldman Barrett (Eds.), Handbook of Emotions (3rd ed., pp. 440-455). New York, NY: Guilford Press.

Leiberg, S., Klimecki, O., \& Singer, T. (2011). Short-term compassion training increases prosocial behavior in a newly developed prosocial game. PLOS ONE, (3), e17798. https://doi.org/10.1371/journal.pone.0017798

Leliveld, M. C., Van Dijk, E., \& Van Beest, I. (2012). Punishing and compensating others at your own expense: The role of empathic concern on reactions to distributive injustice. European Journal of Social Psychology, 42(2), 135-140. https://doi.org/10.1002/ejsp.872

Lerner, M. (1980). The belief in a just world. Boston, MA: Springer.

Lotz, S., Okimoto, T. G., Schlösser, T., \& Fetchenhauer, D. (2011). Punitive versus compensatory reactions to injustice: Emotional antecedents to third-party interventions. Journal of 
Experimental Social Psychology, 47, 477-480. https://doi.org/10.1016/j.jesp.2010.10.004

Lu, T., \& McKeown, S. (2018). The effects of empathy, perceived injustice and group identity on altruistic preferences: Towards compensation or punishment. Journal of Applied Social Psychology. https://doi.org/10.1111/jasp.12558

Lupfer, M. B., Weeks, K. P., Doan, K. A., \& Houston, D. A. (2000). Folk conceptions of fairness and unfairness. European Journal of Social Psychology, 30, 405-428. https://doi.org/10.1002/(sici)1099-0992(200005/06)30:3<405::aid-ejsp997>3.0.co;2-u

McAuliffe, K., Blake, P. R., Steinbeis, N., \& Warneken, F. (2017). The developmental foundations of human fairness. Nature Human Behaviour. https://doi.org/10.1038/s41562-016-0042

Messick, D. M. (1995). Equality, fairness, and social conflict. Social Justice Research, 8, 153-173. https://doi.org/10.1007/BF02334689

Messick, D. M., Bloom, S., Boldizar, J. P., \& Samuelson, C. D. (1985). Why we are fairer than others. Journal of Experimental Social Psychology, 21, 480-500. https://doi.org/10.1016/0022$1031(85) 90031-9$

Mikula, G., Scherer, K. R., \& Athenstaedt, U. (1998). The role of injustice in the elicitation of differential emotional reactions. Personality and Social Psychology Bulletin, 24, 769-783. https://doi.org/10.1177/0146167298247009

Oceja, L. V., Heerdink, M. W., Stocks, E. L., Ambrona, T., López-Pérez-B., \& Salgado, S. (2014). Empathy, awareness of others, and action: How feeling empathy for one-among-others motivates helping the others. Basic and Applied Social Psychology, 36, 111-124. https://doi.org/10.1080/01973533.2013.856787

Peer, E., Samat, S., Brandimarte, L., \& Acquisti, A. (2017). Beyond the Turk: Alternative platforms for crowdsourcing behavioral research. Journal of Experimental Social Psychology, 70, 153163. https://doi.org/10.1016/j.jesp.2017.01.006

Penner, L. A., Dovidio, J. F., Piliavin, J. A., \& Schroeder, D. A. (2005). Prosocial behavior: Multilevel 
perspectives. Annual Review of Psychology, 56, 365-392.

https://doi.org/10.1146/annurev.psych.56.091103.070141

Platow, M. J., Hunter, J. A., Branscombe, N. R., \& Grace, D. M. (2014). Social creativity in Olympic medal counts: Observing the expression of ethnocentric fairness. Social Justice Research, 27, 283-304. https://doi.org/10.1007/s11211-014-0219-1

Radburn, M., Stott, C., Bradford, B., \& Robinson, M. (2016). When is policing fair? Groups, identity and judgements of the procedural justice of coercive crowd policing. Policing and Society. https://doi.org/10.1080/10439463.2016.1234470

Rucker, D.D., Preacher, K.J., Tormala, Z.L., \& Petty, R.E. (2011). Mediation analysis in social psychology: Current practices and new recommendations. Social and Personality Psychology Compass, 5, 359-371.

Schroeder, D., Steel, J., Woodell, A., \& Bembenek, A. F. (2003). Justice within social dilemmas. Personality and Social Psychology Review, 7, 374. Retrieved from http://psr.sagepub.com/cgi/content/abstract/7/4/374\%5Cnhttp://psr.sagepub.com/content/7/4/374. short

Small, D. A., \& Simonsohn, U. (2008). Friends of victims: Personal experience and prosocial behavior. Journal of Consumer Research, 35, 532-542. https://doi.org/10.1086/527268

Starmans, C., Sheskin, M., Bloom, P., Christakis, N. A., \& Brown, G. D. (2017). Why people prefer unequal societies. Nature Human Behaviour, 1, 0082. https://doi.org/10.1038/s41562-017-0082

van Doorn, J., Zeelenberg, M., \& Breugelmans, S. M. (2014). Anger and prosocial behaviour. Emotion Review, 6, 261-268. https://doi.org/10.1177/1754073914523794

van Kleef, G. A. (2009). How emotions regulate social life: The emotions as social information (EASI) model. Current Directions in Psychology, 18, 184-188. https://doi.org/10.1111/j.14678721.2009.01633.x

van Prooijen, J. W. (2010). Retributive versus compensatory justice: Observers' preference for 
punishing in response to criminal offenses. European Journal of Social Psychology, 40, 72-85. https://doi.org/10.1002/ejsp

van Zomeren, M., Spears, R., Fischer, A. H., \& Leach, C. W. (2004). Put your money where your mouth is! Explaining collective action tendencies through group-based anger and group efficacy. Journal of Personality and Social Psychology, 87, 649-664. https://doi.org/10.1037/00223514.87.5.649

Vezzali, L., Stathi, S., Crisp, R. J., Giovannini, D., Capozza, D., \& Gaertner, S. L. (2015). Imagined intergroup contact and common ingroup identity: An integrative approach. Social Psychology, 46, 265-276. https://doi.org/10.1027/1864-9335/a000242

Weiss, H. M., Suckow, K., \& Cropanzano, R. (1999). Effects of justice conditions on discrete emotions. Journal of Applied Psychology, 84, 786-794. https://doi.org/10.1037/00219010.84.5.786

Weng, H. Y., Fox, A. S., Hessenthaler, H. C., Stodola, D. E., \& Davidson, R. J. (2015). The role of compassion in altruistic helping and punishment behavior. PLOS ONE, 10, 1-20. https://doi.org/10.1371/journal.pone.0143794

Will, G. J., Crone, E. A., Bos, W. van den, \& Güroğlu, B. (2013). Acting on observed social exclusion: Developmental perspectives on punishment of excluders and compensation of victims. Developmental Psychology, 49(12), 2236-2244. https://doi.org/10.1037/a0032299 